\title{
DISTANCE LEARNING VIA SOCIAL MEDIA
}

\author{
Mohammad Derawi \\ Smart Wireless Systems, \\ Norwegian University of Science and Technology, Norway
}

\begin{abstract}
In this research work, we examine one of the most applied networking website, namely the Facebook, for conducting courses as a replacement of valuable classical electronic learning platforms. At the initial stage of the Internet community, users of the Internet used email as the main communication mean. Even though email is still the indispensable approach of communication in a appropriate but offline mode, other services were presented, such as many Instant Messaging (IM) software applications like ICQ, Skype, Viber, WhatsApp, Instagram, Musical.ly and Messenger, which let people connect in a real-time mode. Nevertheless, the communication between people was further improved to the next phase, when Facebook came to reality as a social networking homepage that supports many features. People do not only link with others, but also establish all kinds of connections between them. Facebook offers rich functionalities for forming associations. The framework of Facebook delivers without charge software that were provided by traditional electronic learning. This research work looks at how people apply Facebook for teaching and learning, together with recommendations provided.
\end{abstract}

\section{KEYWORDS}

E-Education, Distance Learning, Social Network Services, Facebook

\section{INTRODUCTION}

The Internet today provides software applications of the necessary communication media for computation purposes. Due to its fame, it has become a need of modern individuals for communication and information sharing purposes. For example, the usual Internet users are using email as a replacement of sending letters via postal [1]. Although emails arrive at the mailboxes of recipients instantly, emails are to be read only when the recipients check their accounts. At the early stage, computers allow instant messaging among Internet users using software talk on UNIX operation system. It enables Internet users to communicate in real-time by sending textual data character by character. However, these applications were not popular among casual Internet users, because they must access to host machines [2].

The extensive use of Facebook is not only due to its popularity, but also due to the support by various devices. Facebook is a web application that can be accessed via any web browser. Besides, many mobile phones are equipped with web browsers, such as Opera Mini (a mobile phone version of Opera web browser), and some are even equipped with dedicated software solely for accessing Facebook, such as Apple iPhone, Samsung, Ultra-mobile PC's, various netbooks and the Apple iPad. The support of Facebook by these mobile devices is a definite advantage of using Facebook for education purposes[3].

Natarajan Meghanathan et al. (Eds) : NeTCoM, CSEIT, GRAPH-HOC, NCS, SIPR - 2017

pp. 45- 55, 2017. (C) CS \& IT-CSCP 2017

DOI : $10.5121 /$ csit.2017.71505 


\section{THE ROLE OF FACEBOOK}

Facebook is a social networking web application that supports the following functions, which are for education purposes[4][5]:

- No Cost - The use of most social media sites including Facebook are free of charge.

- No prerequisite - Any Internet user with a valid email address is allowed to register

- Group - It supports user-defined groups so that users can be divided into groups. There are private groups and public groups. The former can only be joined by users via invitation and the latter is open to all. On the other hand, Facebook page enables any student to join the page for accessing the teaching materials and to be notified by any update of the page.

- Page - It enables users to create Facebook pages for particular organizations, so that other users can join the group and will be informed of all updates to the Facebook pages.

- Privacy - It supports the control of privacy in terms of items posted, users and groups. In other words, it is possible to set the access control privileges of individual items posted, users and groups.

- Notifications - It supports user notifications of all updates of items, users and groups via emails. If there is any update of an item, a user or a group, emails are sent to the related users for notifications.

- Photo albums - It supports user and group level photo albums.

- Discussions - It supports discussions with respect to a message, a photo, a photo album or an article.

- Emails - It supports internal emails between any two Facebook users, and it is possible to send an email to all users of a group.

- Events - It supports events and is possible to create events for a group. Users to indicate whether they will be present or absent from the events.

- User main page - The main page of a Facebook user shows all the updates to friends, the groups joined, and all the upcoming events.

- Chatting - Facebook support real-time chatting through the web browser.

- User-defined software - There is a well-defined Facebook API (Application Program Interface) so that software developers can develop software to be executed within the Facebook webpage. For example, quiz creator software enables any Facebook user to create a survey, questionnaire or quiz easily. Furthermore, applications for file sharing allows users to share their own documents with any other users. Besides, some Facebook applications are educational [10] .

- Activity log - All operations by any Facebook user are logged with timestamps and can be traced. 
- Live Video - On April 62016 last year, Facebook started this extremely great service, where you have real-time video conversations with others. A fascinating service.

\section{FACEBOOK AS AN EDUCATIONAL PLATFORM}

It is conceivable to use Facebook as a social network for education purpose as follows:

- User creations - Teaching staff and students need to access the Facebook website for registration. Preferably, they all use their email accounts granted by the universities, so that it is easier for them to locate one another. Furthermore, each of them can keep their own personal Facebook accounts for their own casual uses, whereas the Facebook student users created by using university accounts are for teaching and learning only if they would like to prevent lectures from accessing their private life in the social networking website. The limitation is that the students may not log on their Facebook that is associated with their university email account daily.

- Course preparations - Teaching staff can create a Facebook page for each course with their Facebook accounts. Each Facebook page can create multiple photo albums and multiple discussions. Therefore, teaching staff can make use of the facilities provided by Facebook to enrich their Facebook page for the course, such as adding links to references materials, discussions or photo albums.

- Teaching materials preparation - For teaching purposes, the most important teaching materials to be distributed are lecture notes or slides. Usually, teaching staff uses Microsoft PowerPoint to prepare the PowerPoint files for students to download. Although there are free Microsoft PowerPoint viewer applications for Windows platforms released by Microsoft, there are platforms and mobile devices that cannot display PowerPoint files properly. Instead, image file format is the universal format for display purposes. It is therefore preferable to convert all PowerPoint files into sequences of images, and upload them as Facebook page photo albums. There are freeware applications that can convert Microsoft Office files into sequences of images. Then, Facebook users will be notified the existing of new slides, which can be accessed by any web-browsing enabled devices. For presentation files other than Microsoft PowerPoint, lectures can also using different applications to convert the files into images for uploading. Most mobile devices can be used for web browsing. Some mobile phones, such as Apple iPhone, are equipped with dedicated components for accessing Facebook. With the existence of mobile network technologies, such as GPRS and HSDPA, students can view the lecture notes as photo albums on the Facebook page for the course anywhere. The teaching materials in Microsoft Office formats can be uploaded to a web server and their URLs can be posted to the Facebook pages. As a result, Facebook student users can determine whether to download the original files. Besides, it is possible to post links of videos or upload video files to the course Facebook page, such as the videos for the lectures or demonstrations.

- Conducting lectures and tutorials - Teaching staff can use the PowerPoint or other presentation files to conduct lectures and tutorials. With Facebook, they have an alternate way to present the notes, which is showing Facebook photo albums for the presentation files. There is an extra benefit of showing a photo album compared with presenting a presentation file, which supports discussions on the entire photo albums and individual slides. Furthermore, while showing a slide as Facebook image, students can add comments to the slide which will notify the teaching staff the existence of comments for immediate feedbacks. It facilitates the discussions among teaching staff and students, especially those who are unwilling to speak in front of other students. Furthermore, if a 
student has any problem on any slide, he or she can add a comment, and a notification email will be sent to the teaching staff. Then the teaching staff can simply click the link embedded in the email to locate the slide (image) the student mentioned and provide feedbacks.

- Discussions - Whenever there is any update to the course group or course page, all involved Facebook student users are notified and can access those changes, such as a posting of links referring to online reference materials, videos and a creation of photo albums. Then, all users can access to those items and leave comments which can be read by other users for discussions. By consolidating the reference materials which originally scattered in the Internet, students time for searching the materials by themselves can be saved. For example, lecture notes can be released as Facebook photo albums, so that all students can access these albums for viewing them. Whenever they have any comments or questions regarding any slides, they can leave comments or questions to them. Teaching staff and other students will be notified of such comments or questions by emails, and leave responses on the slide. Since Facebook is informal, users are more willing to leave messages on them. It actually motivates students to share and discuss for peer-to-peer learning. In fact, there are many interactive applications developed for Facebook. Lectures can make appropriate use of those external applications to facilitate interactions among lecturers and students.[6]

- Assessments - Facebook provides application programming interface (API) for software developers to develop Facebook applications. As such, there have been a lot of applications available for Facebook users. There are several Facebook applications which enable Facebook users to create quizzes, such as the Quizzes and Quiz Creator applications. By using these software, teaching staff can create a quiz, such as for each lecture, and post the link to the course page, and inform students to take the quiz to examine their understandings on the course materials. In addition, file sharing applications allow students submit assignments to teachers easily. As Facebook can be accessed by any web browser, students can increase their understanding on the course materials, anytime and anywhere. [7]

- Personal notes and private files - Students can make use of notes function in Facebook to keep their personal study notes. They can either keep the notes private or share the notes with others. Private files can be sent using the private message function with attachment. [8]

- Privacy, security and legal issues - Facebook provides customization in course account setting that protect privacy and ensure security of course access. The course creator can set the access of content to their students only by using the "add friend" function and "controlling how you share" function properly. Account and privacy setting can be performed under the "Account" session in Facebook. Regarding the legal issues of posting teaching materials in the social networking website, the lecturers should well aware of the terms and agreements listed in Facebook. By using Facebook appropriately, education functions can be delivered via this platform effectively.[9]

\section{Case Study}

In this case study, a course is used for illustration purposes. Upon the creation of Facebook account by a teaching staff, the lecturer can create a Facebook page for the course with the given course code. For creating the course account, the teaching staff, clicked the Drop down arrow and "Create Page"' to create a new page for the course as shown in Figure 1 


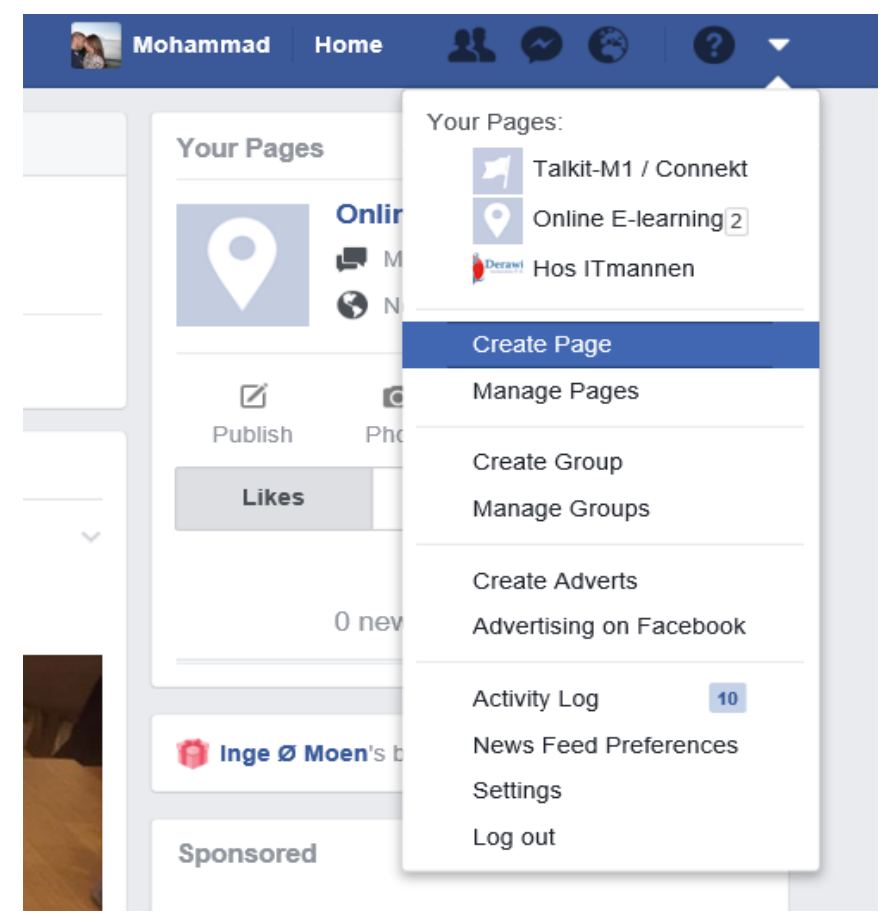

Figure 1. Facebook page for personal profile creation

By clicking "Create Page to start creating the page for the course", the teaching staff can specified the course details on the webpage as in Figure 2 below. Finally, the teaching staff clicked "Create Page" to create the course page. Then, the lecturer could create photos albums for the lecture notes. The lecture clicked "Photos" to create a new photo album.

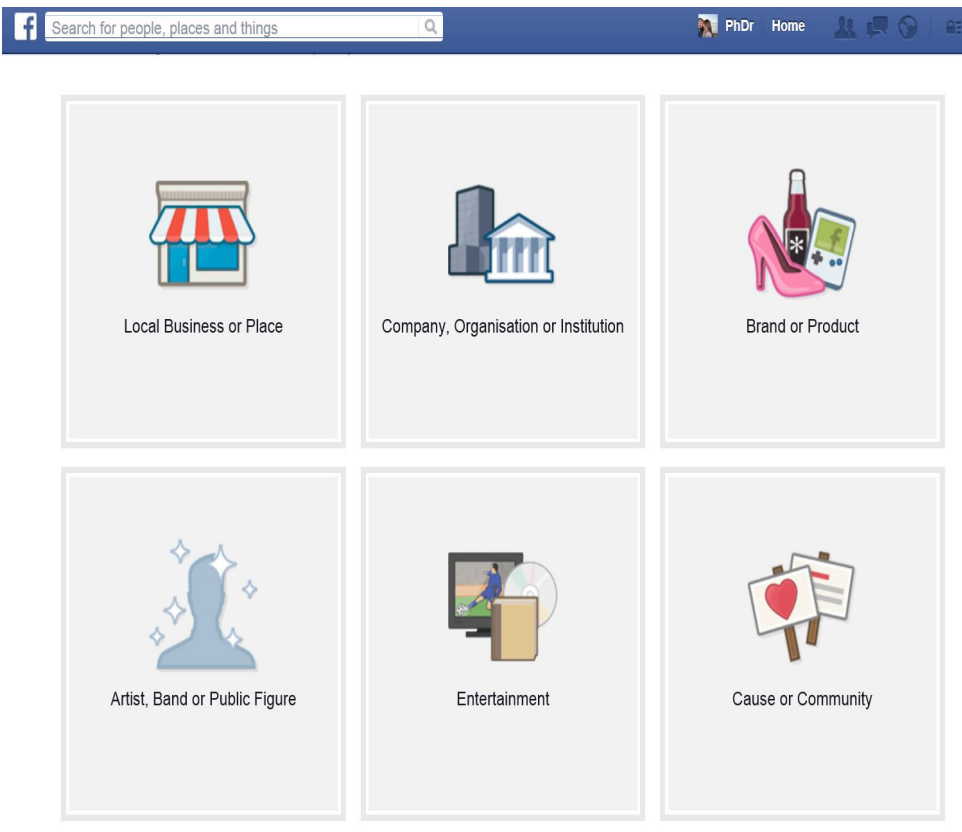

Figure 2. Facebook page for course main menu 
The lecturer then started uploading the lecture notes images to the photo album. Since different web browsers support different approaches of uploading images to a photo album, for example, Microsoft Internet Explorer and Google Chrome can make use of a Facebook plugin whereas Firefox uses a Java based component, the lecturer would experience different interface when using different web browsers. Once the photo album was created, the lecturer reviewed the images and rearranged the sequence of the images as necessary. Then, the photo album with lecture notes was ready to be accessed by students.

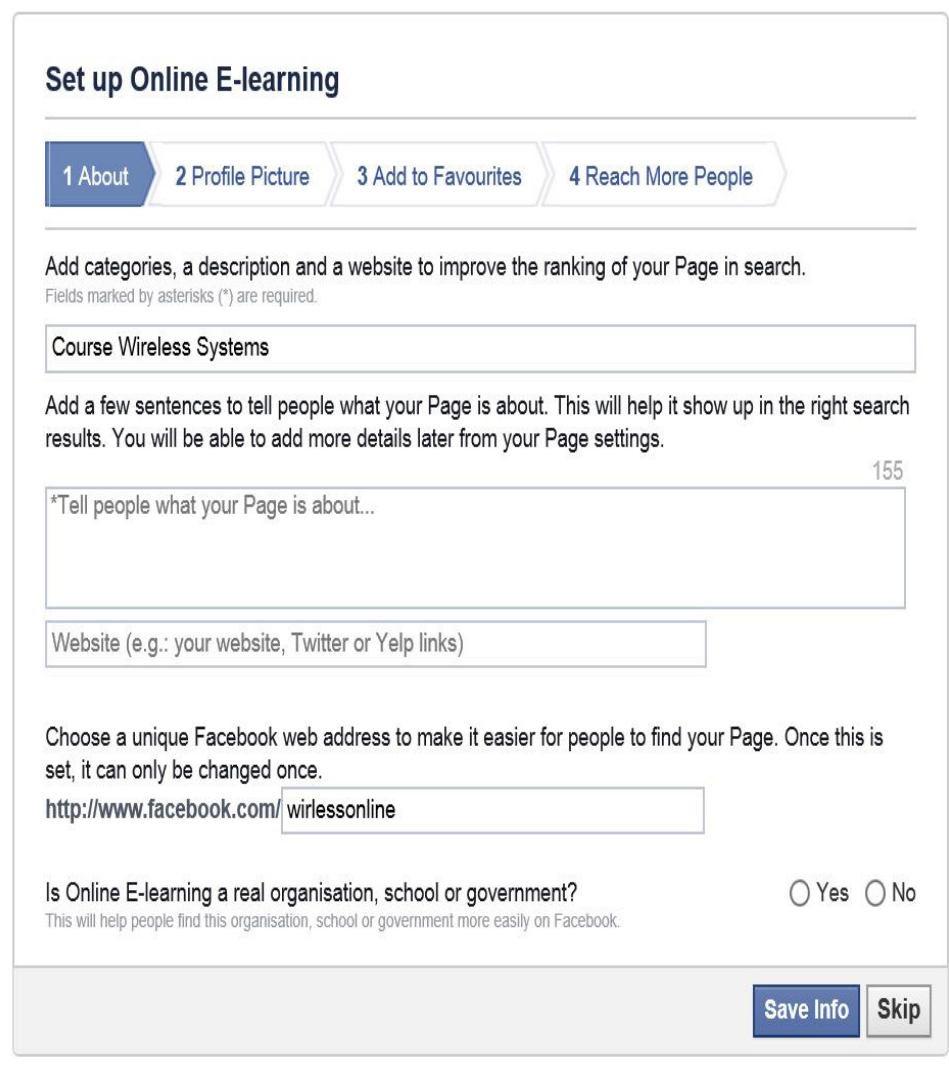

Figure 3. Facebook page for course description

For those students who would like to receive notification of course notes publishing, the lecturer could instruct them to use the function of adding themselves as fans of the course page. The lecturer could either rearrange the images or add new images by clicking "Organize Photos" or "Add Photo" buttons. For any further updates of the album, students with the role of fans of the course page would receive new notifications about the changes. The overview of the album is shown in Figure 4 and a screen showing the course content is shown in Figure 5. 
Photos 1 - 20 out of $\mathrm{j}$ | Dack to C5J462 - Introduction to Databose Systems's Photos | Cdit Photos | Organize Photos | Add More Photos

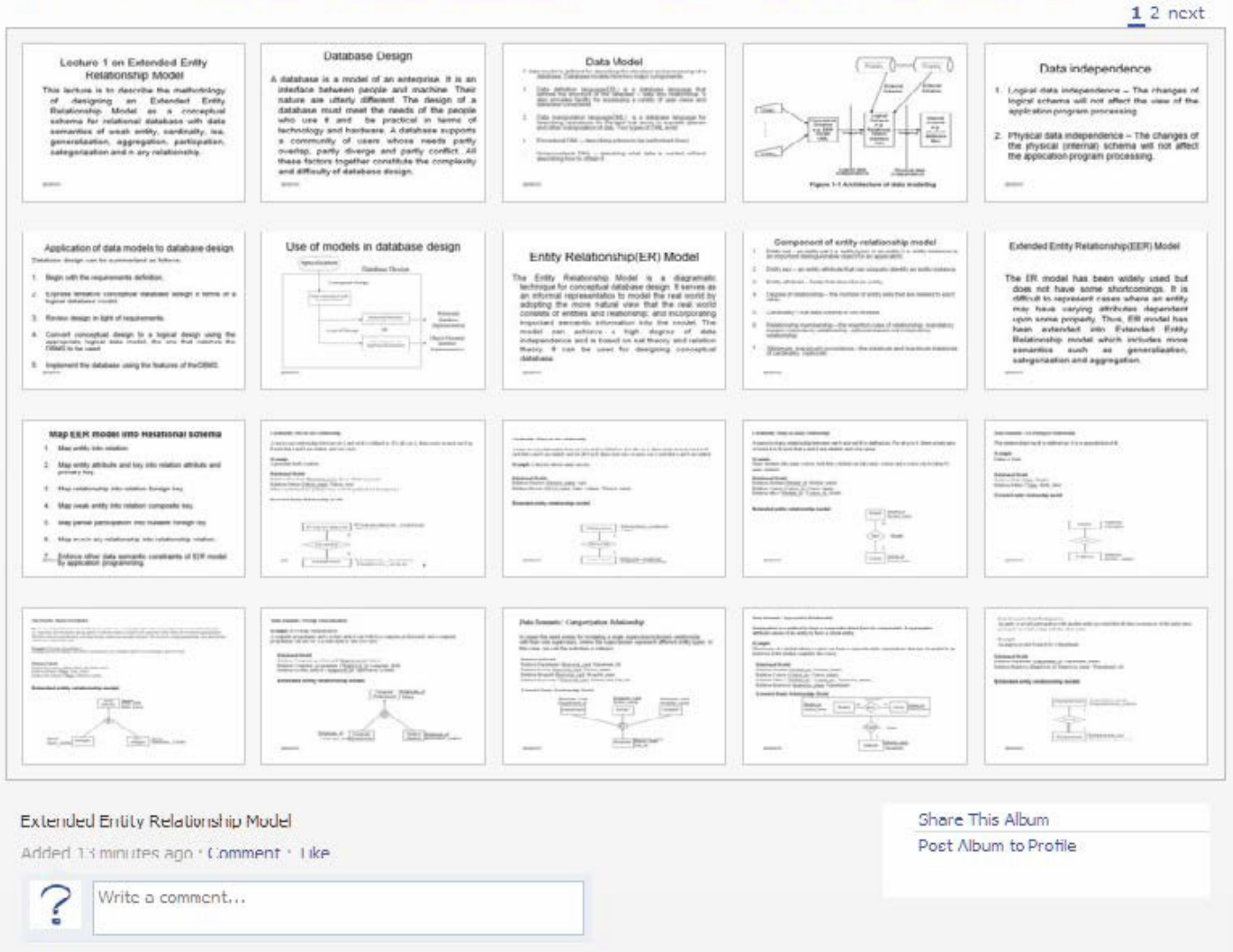

Figure 4. Facebook page for course slides

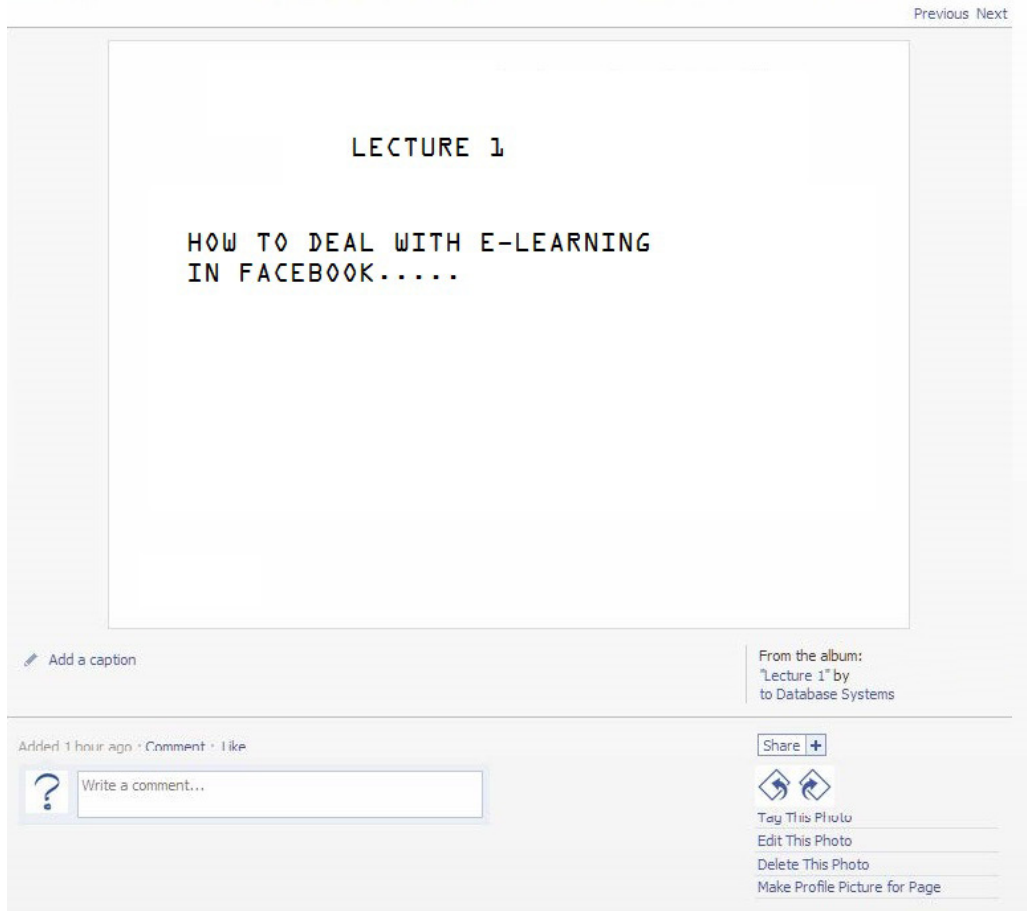

Figure 5. Facebook page for course slide presentation 
The lecturer could make use of other Facebook features in the main profile of the course page to provide further support to the students:

- Link - teaching staff can add the reference materials on the web page with a link, such as reference articles, videos and so on.

- Event - teaching staff can create events for lectures and tutorials, so that student users will be notified and their main page will show the schedules of the lectures and tutorials whenever the students users log on Facebook.

- Video - if the lecture, tutorial or demonstration is recorded, it is possible to update it to the Facebook page, so that it is accessible easily by the students.

If the presentation file does not involve any transition effects, teaching staff could use the Facebook photo album web page to conduct the lecture/tutorial. The benefit was that if students wanted to raise any question and provide any feedback on the slide, they could post their comments for such slide and the teaching staff would be notified immediately. Such feature was especially useful to students who were passive in the class. The comments posted were specific to individual slide and it therefore facilitates the discussion among teaching staff and students.

Students could also access to the photo album with their own mobile devices, such as mobile phones. Although the devices were small, they support zooming and enabled the students to provide feedbacks or comments similar to a computer. For example, Figure 6 shows the same lecture note slide to be shown by an Apple iPhone and a LG mobile phone respectively.

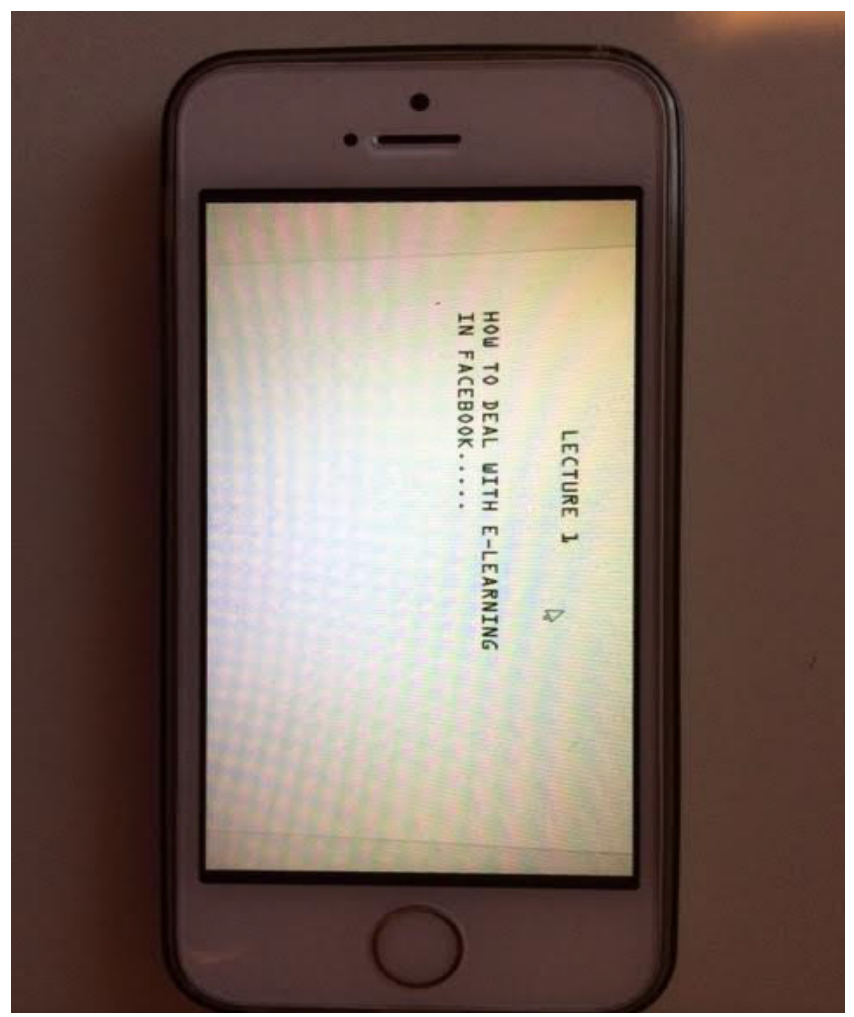

Figure 6. The image for a lecture note slide is shown by an Apple iPhone. The same will also appear in a LG mobile phone 
For slide with text in smaller typeface, most mobile phones enable users to zoom the images for better readability. When students wanted to leave comments or questions regarding the slide, they used their mobile device to do so. For example, Figure 7 shows the user interfaces of an Apple iPhone and a LG mobile phone, which enables Facebook student users to post comments to a slide.

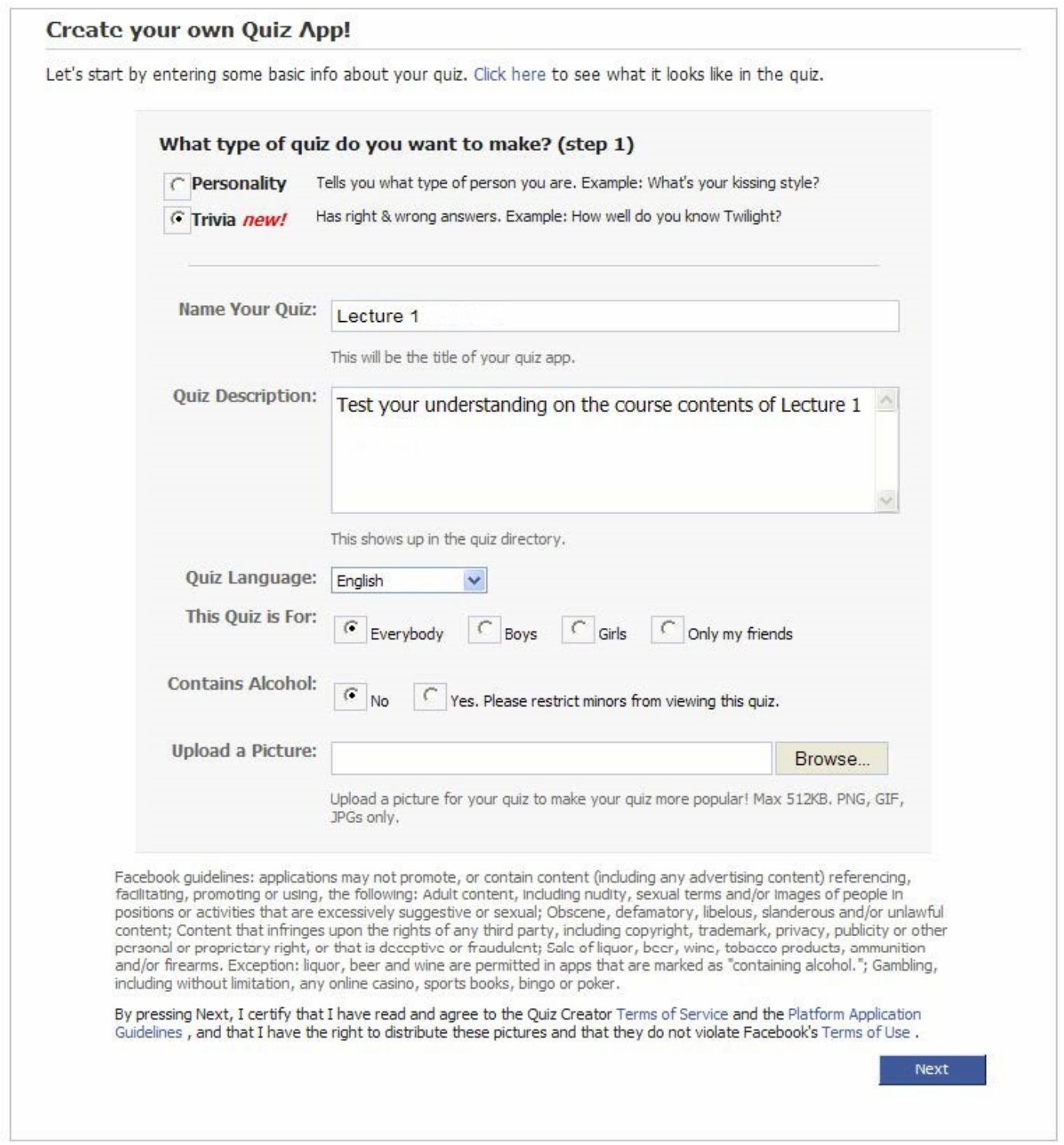

Figure 7. Specify the quiz name and details with Quiz Creator

In fact, mobile devices are capable of viewing the slide and enable students to leave comments or questions to particular slide. Upon receiving comments or questions, all members in the course, including teaching staff, would be notified. As soon as teaching staff received a notification emails from Facebook, they could click the embedded link that navigates the web browser to the referred slide, and leave another comment for the same slide as responses. Teaching staff could create quizzes to assess students' understandings of the lecture. For example, Figure 8 illustrate the use of Quiz Creator Facebook application by a teaching staff to create a quiz. 


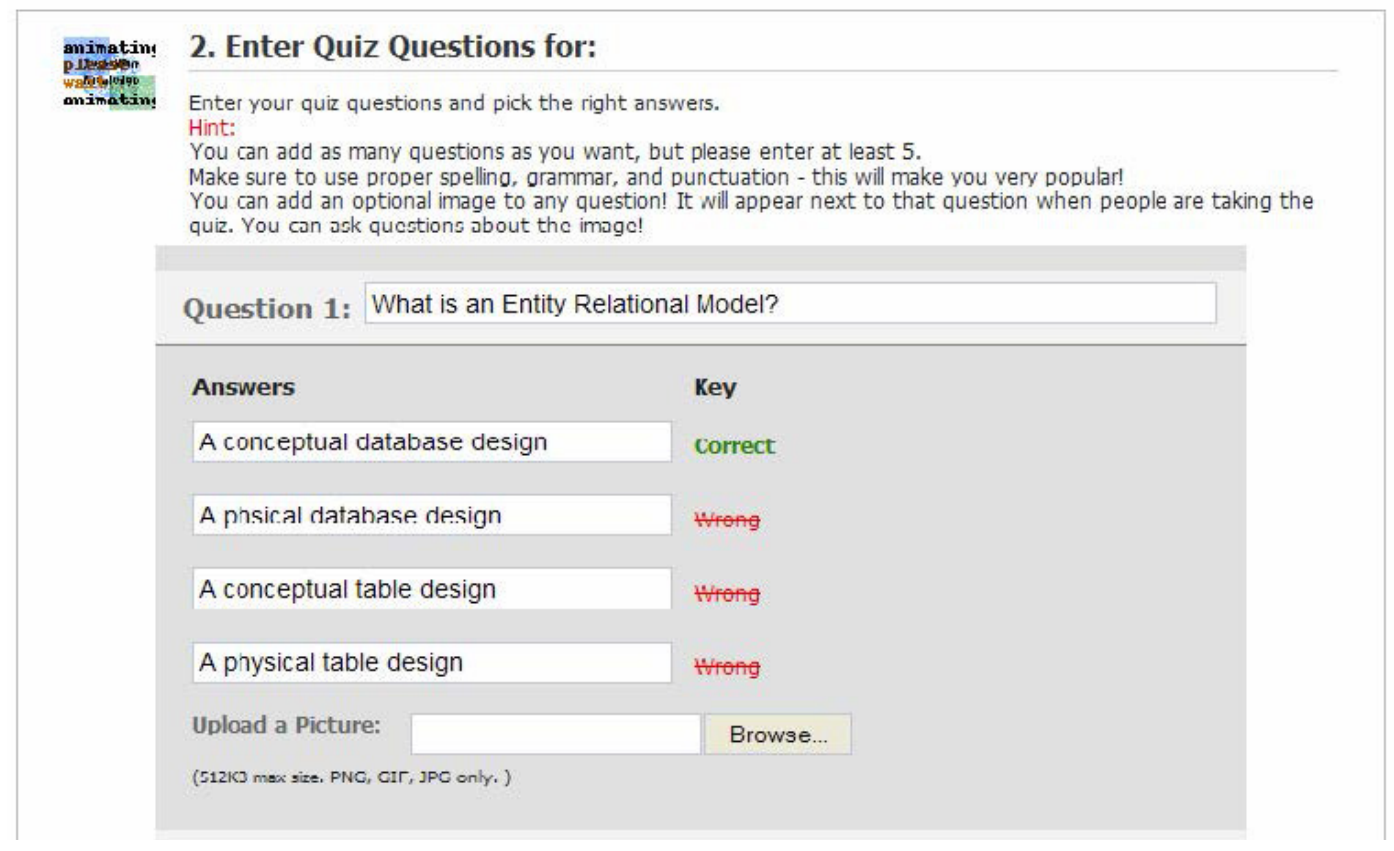

Figure 8. Specify the quiz questions and answers with Quiz Creator

\section{CONCLUSION}

The social networking site - Facebook is the most popular web site today, and students today do not need any training on its practice. In addition, any pc and smart device can effortlessly access it with web browsing competence. Thus, Facebook becomes an excellent additional education framework that can replace some features of traditional classroom learning. We also see today that more and more universities today are applying Facebook in a different level. In summary, the use of Facebook for education has many benefits. First, true cross platforms and cross devices such as pc and smart device support Facebook. Second, course-teaching materials are easily spread. Third, blog-like discussion or video chatting on individual items as well as online quizzes and assessments are supported. Fourth, it is user-friendly and no special trainings are obligatory. The points deliver some visions for one to develop a student friendly platform for informationsharing.

\section{REFERENCES}

[1] E-learning Systems, http://www.bapsis.com/elearningsystems.htm, [On-line; accessed 19-September2014].

[2] Craciunas, S. \& Elsek, I, (2009) The standard model of an e-learning platform, Bucharest, Romania, (Chapter 2).

[3] Dobre, I., (2010) Critical Study of the present e-learning systems, Academia Romana, Romania, (Chapter 2).

[4] Edgar, R. W., (2005) Security in e-learning, Springer. Vienna University of Technology, Austria, (Chapter 1).

[5] Iacob, N., (2010). Data replication in distributed environments, Proceedings of International Scienti.c Conference ECO-TREND: Brancusi University Targu Jiu, 629-634. 
[6] Jalal, A. \& Ahmad, M., (2008). Security Enhancement for E-Learning Portal, Proceedinggs of International Journal of Computer Science and Network Security, Department of Computer Science City University, Peshawar, Pakistan, 41-45.

[7] Kritzinger, E. \& Solms S., (2006). E-learning: Incorporating Information Security Governance, Proceeding of Informing Science and IT Education Conference, Salford (Greater Manchester), England, 319-325.

[8] Kumar, S. \& Kamlesh, D., (2011). Investigation on Security in LMS Moodle, Proceedinggs of International Journal of Information Technology and Knowledge Management, Kurukshetra University, Kurukshetra, India, 233-238.

[9] Przemek, S. (2007), PHP Session Security, Poland, (Chapter 1).

[10] Smeureanu, I. \& Isaila, N, The Knowledge Transfer Through E-Learning in Business Environment, Economy Informatics, 97-98.

\section{AUTHORS}

Mohammad Derawi received his diplomas in Computer Science engineering from the Technical University of Denmark where he received both a BSc (2007) and Msc (2009) degree. In addition he received the title as the youngest engineer of Denmark in 2009. Derawi has pursued his PhD in information security at the Norwegian Information Security Laboratory (NISLab). His research interest included biometrics with specialization on gait recognition and fingerprint in mobile devices. Derawi was active in the 7th Framework European project "TrUsted Revocable Biometric IdeNtitiEs" (TURBINE, www.turbine-project.eu) and other main interests of areas include biometrics. Today he holds an full professor position and received the title as the youngest professor of Norway within Electronic Engineering and is specialised within

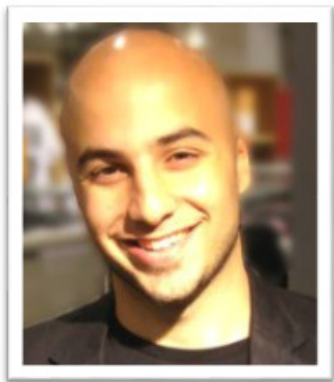
Information Security, Biometrics, Smart Devices, Multimedia, Programming and Micro-Controllers. 